\title{
Corrigendum: On the speed of piezostrain-mediated voltage-driven perpendicular magnetization reversal: a computational elastodynamics-micromagnetic phase-field study
}

\author{
Ren-Ci Peng, Jia-Mian Hu, Long-Qing Chen and Ce-Wen Nan
}

NPG Asia Materials (2017) 9, e446; doi:10.1038/am.2017.193; published online 27 October 2017

Correction to: NPG Asia Materials advance online publication 7 July 2017; doi:10.1038/am.2017.97

After online publication of this article, the authors noticed a typographical error in the main text under the Methods section.

On the bottom right of Page 3, the original text ' $\ldots, c_{12}=93.46 \times 10^{11}$ $\mathrm{GPa} . .$. ' should read as ' $\ldots, c_{12}=93.46 \mathrm{GPa} \ldots$ '

The authors apologize for any inconvenience caused. The error has been corrected in the HTML and PDF versions of the article. (c) (i) This work is licensed under a Creative Commons Attribution 4.0 International License. The images or other third party material in this article are included in the article's Creative Commons license, unless indicated otherwise in the credit line; if the material is not included under the Creative Commons license, users will need to obtain permission from the license holder to reproduce the material. To view a copy of this license, visit http:// creativecommons.org/licenses/by/4.0/

(C) The Author(s) 2017 